\title{
Research of Ship's Stealth Methods in Static Electric Field
}

\author{
Peng Yu, Jinfang Cheng and Runxiang Jiang
}

Naval University of Engineering, Wuhan Hubei 430033 China

Keywords: warship, electric field, stealth, anti-corrosion, Advanced ICCP, impressed-current compensation

\begin{abstract}
In order to decrease the ship's static electric field as much as possible, the ship potential and static electric field are compared under different conditions, natural corrosion, sacrificial anodes protection, normal and advanced impressed-current cathodic protection and impressed-current compensation based on boundary element calculating software. Then a scaled ship model experiment was conducted for the validation of numerical results. The results show that the method based on impressed-current compensation can most effectively decrease the ship's static electric field compared with other methods, but the whole ship areas are not under cathodic protection.
\end{abstract}

\section{Introduction}

Ship's static electric field is a vital passive attack source for underwater weapon, whose electric field intensity can reach a level of $\mathrm{mV} / \mathrm{m}$ in near field ${ }^{[1,2]}$, vulnerable to be attacked by mine with electric field fuze, like Russian "MDM-6" [3], Italian "ASTERIA" [4] and Spanish "MINEA", et al. In order to increase the stealth performance in electric field, electric field suppression techniques has been used in the design and manufacturing of the ship in many countries ${ }^{[5,6]}$.

As ship's static electric field is mainly caused by corrosion and anti-corrosion electric current, there are several common methods to decrease the intensity of electric field, optimizing the structure process $^{[7]}$, impressed current compensation ${ }^{[8]}$ and Advanced ICCP(advanced impressed-current cathodic protection) ${ }^{[9,11]}$, et al. As the ship's serving time goes longer, the coating condition gradually becomes serious, and thus the electric field signal increases. In order to decrease the electric field more, Advanced ICCP and impressed-current compensation methods are commonly used around the world, like the Russian "Каскад-э" system using impressed-current compensation method, and American "Advanced ICCP" system.

Impressed-current compensation method and Advanced ICCP method have different evaluation criterions in decreasing ship's static electric field according to various articles, as they have different working principle. In order to make it clear the relationship between impressed-current compensation and Advanced ICCP, and confirm the most effective method in decreasing the ship's static electric field, a medium ship was simulated by BEM( Boundary Element Method ) software and a scaled ship model experiment is taken, comparing the electric filed and surface potential of the ship.

\section{Static Electric Field Stealth Methods}

\subsection{Structural Process}

Optimizing the structural process not only helps the anti-corrosion ability of ship, but also decreases the intensity of static electric field. The main methods include: the rational use of dielectric materials and coatings, the electrical isolation measures to increase the resistance of the electric field source, reduce the number of dissimilar metals and the use of metals with small electrode potential difference, reasonable shielding of the electric field source and several other methods ${ }^{[8]}$.

\subsection{Impressed-Current Compensation Methods}

With the increase in service life of the ship, the aging of the electrical insulation layer will lead to a significant reduction in the performance of the electrical isolation measures, which will still produce major static electric fields. In order to reduce the static electric field signal generated by "hull - sea propeller" corrosion circuit loop more effectively, impressed-current compensation methods can be used to further reduce the static electric field signal. The fundamental of impressed the current 
compensation methods is to provide current opposite to the natural corrosion current, the basic principle shown in Figure 1, where the solid line for the corrosion current, the dotted line for the compensation current, $\mathrm{R}$ is the internal loop resistance between hull and propeller

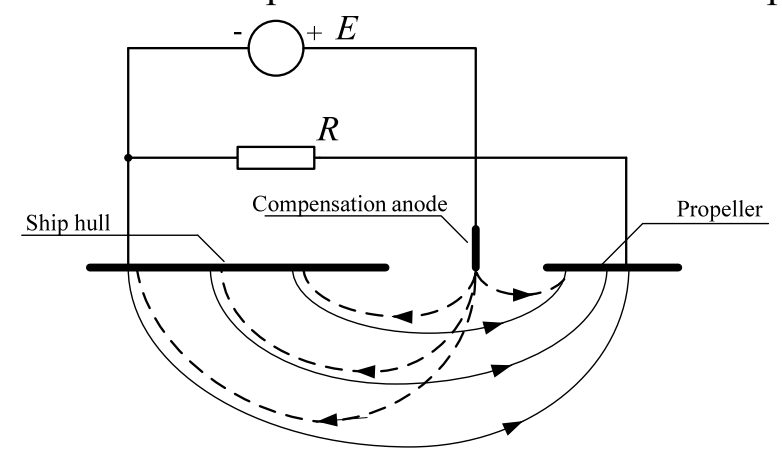

\subsection{Cathodic Protection optimization}

Fig. 1 Schematic diagram of impressed-current compensation

Cathodic protection optimization method is also known as Advanced ICCP method when the anticorrosion current is provided by external DC source not the sacrificial anodes. The cathodic protection method mainly used for anti-corrosion for ship will produce a large anti-corrosion current, so that the ship static electric field increases a lot at the same time. In order to take into account both the anticorrosion and electric field stealth, simulation software (such as "CP Master", "PROCA", "COMCAP" and "BEASY", et al. ) and scaling ship model similar to the ship's actual line type can be used to optimizing the sacrificial anodes cathodic protection System or the impressed-current cathodic protection system, making the distribution of the protection current more uniform on the surface of ship. The specific methods mainly include optimizing the number and positions of reference electrodes, auxiliary anodes or sacrificial anodes.

\section{Simulation and Comparison}

In order to compare the electric field and surface potential of ship under different condition, finding the method which can decreasing the electric field most. The BEM software is used to simulate a ship, whose length $\mathrm{L}=130 \mathrm{~m}$, wide $\mathrm{B}=15 \mathrm{~m}$, draught $\mathrm{T}=4 \mathrm{~m}$. The origin of coordinates lies in the center of the bottom ship surface, as shown in Figure 2. The coordinates of the bow and stern of the ship are $65 \mathrm{~m}$ and $-65 \mathrm{~m}$ respectively. The surface materials of the hull is steel with $2 \%$ coating breakage, and the propeller uses nickel aluminum bronze, the polarization curve of hull and propeller is shown in figure 3 .

\section{$A_{\theta_{2}}^{r^{2}}$}

Fig. 2 the structure of ship

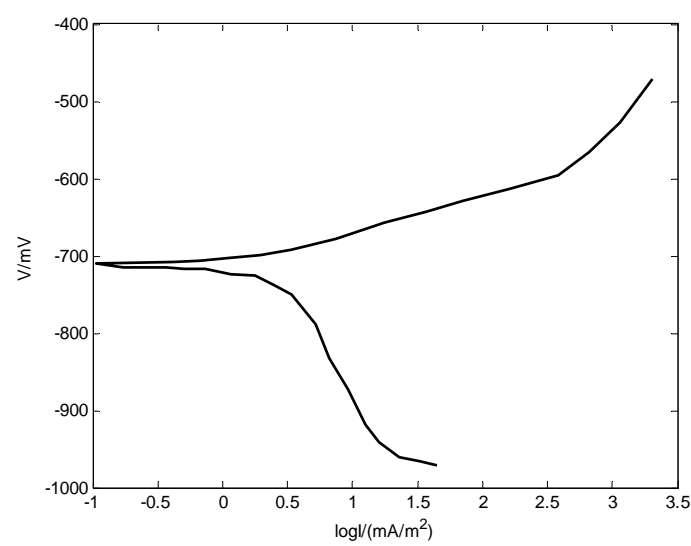

(a) The polarization curve of hull

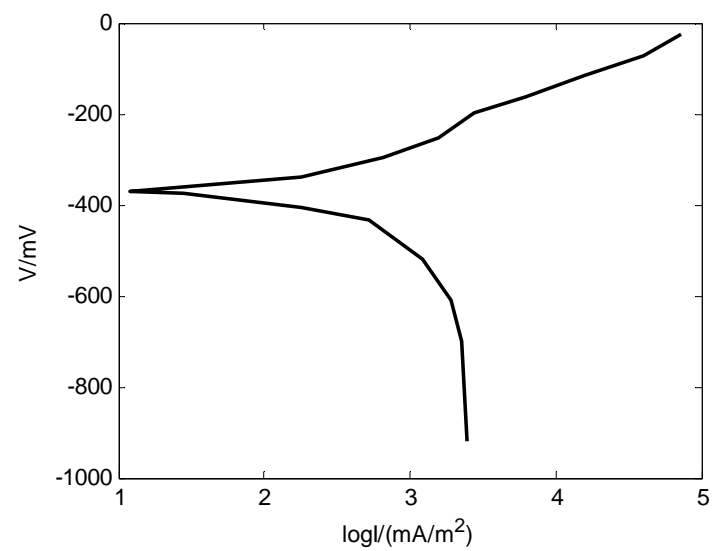

(b) The polarization curve of propeller

Fig. 3 polarization curve of different materials 
The water conductivity is $4 \mathrm{~S} / \mathrm{m}$ (depth $60 \mathrm{~m}$ ) and seabed conductivity is $0.1 \mathrm{~S} / \mathrm{m}$, then calculates the electric field and underwater hull surface potential value under different condition, using the boundary element software.

\subsection{Natural Corrosion State}

Table 1 shows the peak-peak value of electric field and the potential in $0 \mathrm{~m}$ abeam distance and different depths, under natural corrosion state. From the available information, we can see that the electric field detection system such as mines use the sensor to measure UEP (underwater electric potential) difference between two points around the ship ${ }^{[12]}$, the electrode distance of current electric field fuze mine is usually $0.5-1 \mathrm{~m}$, the signal is approximately the electric field signal. To this end, this article uses the electric field $|\mathrm{E}|$ value as the evaluation index.

Table 1. Peak to peak value of $|\mathrm{E}|$ and $U$ under natural corrosion

\begin{tabular}{cccc}
\hline No. & Water depth & Peak-peak value of $|\mathrm{E}|(\mu \mathrm{V} / \mathrm{m})$ & Peak-peak value of $\mathrm{U}(\mathrm{mV})$ \\
\hline 1 & $0.5 \mathrm{~B}$ & 5824.52 & 32.84 \\
2 & $12 \mathrm{~m}$ & 2068.76 & 20.57 \\
3 & $1.0 \mathrm{~B}$ & 829.52 & 13.14 \\
4 & $1.5 \mathrm{~B}$ & 289.49 & 8.14 \\
\hline
\end{tabular}

It can be seen from Table 1 that, the ship static electric field in the near field can up to $\mathrm{mV} / \mathrm{m}$ order of magnitude, under natural corrosion, which can easily be detected. With the increase of water depth, the underwater electric field signal gradually weakened, which is mainly because the charge potential and electric field attenuation characteristics.

\subsection{Whole Ship Sacrificial Anodes Protection State}

Sacrificial anodes provide the required cathodic protection current, so that the potential of the metal is in cathodic protected potential range (usually $-750 \mathrm{mV} \sim-1000 \mathrm{mV}$ ), achieving the best protection of ship ${ }^{[13]}$. According to the polarization curve in Fig 3, the cathodic polarization current density of hull and propeller is about 100 and $500 \mathrm{~mA} / \mathrm{m}^{2}$ respectively, when the material is protected.

Table 2. Peak to peak value of $|\mathrm{E}|$ and $U$ under sacrificial anodes

\begin{tabular}{cccc}
\hline No. & Water depth & Peak-peak value of $|\mathrm{E}|(\mu \mathrm{V} / \mathrm{m})$ & Peak-peak value of $\mathrm{U}(\mathrm{mV})$ \\
\hline 1 & $0.5 \mathrm{~B}$ & 23340.96 & 106.43 \\
2 & $12 \mathrm{~m}$ & 7225.24 & 59.45 \\
3 & $1.0 \mathrm{~B}$ & 2588.32 & 34.68 \\
4 & $1.5 \mathrm{~B}$ & 800.72 & 19.69 \\
\hline
\end{tabular}

The protection current required for the hull with a flooding area of $2351.6 \mathrm{~m}^{2}$ is $23.5 \mathrm{~A}$ and the protection current of the propeller is $33.08 \mathrm{~A}$. The anode using $\mathrm{Al}$ material base (size $1000 \mathrm{~mm} * 120$ $\mathrm{mm} * 50 \mathrm{~mm}$ ), so the number of blocks is 20 according to its current output capability. The optimal position of sacrificial anode is obtained by simulation of boundary element software. At this time, the total output current of sacrifice anode is $41.105 \mathrm{~A}$. The peak- peak value of the electric field and the potential under the keel are shown in Table 2.

\subsection{Impressed-Current Cathodic Protection and optimization}

Impressed-current cathodic protection uses external DC source to provide cathodic current for the metals protected, so that material is polarized, achieving the purpose of cathodic protection [13-14]. Compared with the sacrificial anodes method, this method has the advantages of long design life, and adjustable output current and potential.

\subsubsection{Impressed-Current Cathodic Protection}

Two pairs of auxiliary anodes ICCP1 and ICCP2 are symmetrical distributed, using the keel as the center line, and their longitudinal distance to the ship tail were $18.2 \mathrm{~m}$ and $52.2 \mathrm{~m}$ respectively, below the waterline $1.5 \mathrm{~m}$. The current values calculated by the boundary element software are: ICCP1 = $16.591 \mathrm{~A}$ and ICCP2 $=32.244 \mathrm{~A}$ respectively and the sum of the biaxial currents is $35.94 \mathrm{~A}$, which is based on the protected potential of the hull. The peak-peak value of the electric field and potential below the keel is shown in Table 3 . 
Table 3. Peak to peak value of $|\mathrm{E}|$ and $U$ under 2 pairs of auxiliary anodes

\begin{tabular}{cccc}
\hline No. & Water depth & Peak-peak value of $|\mathrm{E}|(\mu \mathrm{V} / \mathrm{m})$ & Peak-peak value of $\mathrm{U}(\mathrm{mV})$ \\
\hline 1 & $0.5 \mathrm{~B}$ & 28299.16 & 145.73 \\
2 & $12 \mathrm{~m}$ & 9796.59 & 81.58 \\
3 & $1.0 \mathrm{~B}$ & 3475.06 & 45.51 \\
4 & $1.5 \mathrm{~B}$ & 1057.15 & 23.86 \\
\hline
\end{tabular}

\subsubsection{Advanced Impressed-Current Cathodic Protection}

In order to make the hull surface potential more uniform, many pairs of auxiliary anodes are used, and the underwater hull of ship are divided to many zones to be protected. The auxiliary anode is symmetrical about the keel and table 4 gives the auxiliary anode mounting position and the output current value of the port side.

Table 4. Locations and output current value of auxiliary anodes

\begin{tabular}{cccccc}
\hline No. & Location $(\mathrm{x}, \mathrm{y}, \mathrm{z})$ & $\mathrm{I}(\mathrm{A})$ & No. & Location $(\mathrm{x}, \mathrm{y}, \mathrm{z})$ & $\mathrm{I}(\mathrm{A})$ \\
\hline 1 & $(27.2,4.79,1.96)$ & 5.0 & 5 & $(-52.15,3.68,3.10)$ & 5.0 \\
2 & $(2.0,6.78,2.04)$ & 4.8 & 6 & $(-56.95,3.18,3.22)$ & 20.0 \\
3 & $(-27.2,6.484,2.40)$ & 4.8 & 7 & $(-61.11,2.22,3.07)$ & 20.0 \\
4 & $(-40.8,4.651,2.15)$ & 3.6 & 8 & $(-65.75,4.07,3.67)$ & 4.8 \\
\hline
\end{tabular}

Comparing Table 3 and Table 5, it can be found that the peak-to-peak value of $|\mathrm{E}|$ reduced about $30 \%$ (from 3475.06 to 2451.24 at 1B depth) when the number of auxiliary anode increased. Mainly because the hull potential becomes more uniform due to more auxiliary anodes.

Table 5. Peak to peak value of $|\mathrm{E}|$ and $\mathrm{U}$ under 8 pairs of auxiliary anodes

\begin{tabular}{cccc}
\hline No. & Water depth & Peak-peak value of $|\mathrm{E}|(\mu \mathrm{V} / \mathrm{m})$ & Peak-peak value of $\mathrm{U}(\mathrm{mV})$ \\
\hline 1 & $0.5 \mathrm{~B}$ & 25605.61 & 100.96 \\
2 & $12 \mathrm{~m}$ & 7258.2 & 52.28 \\
3 & $1.0 \mathrm{~B}$ & 2451.24 & 28.36 \\
4 & $1.5 \mathrm{~B}$ & 704.7 & 15.01 \\
\hline
\end{tabular}

Comparing Table 2 and Table 5 , it can be found that the underwater electric field intensity is basically the same. In fact, the principle of external current cathodic protection and the whole ship sacrificial anodes protection are basically the same in the ship stealth and anti-corrosion aspect, but the sacrificial anode output current is not under control, when the ship coating resistance, speed and other external conditions changed, its existing anti-corrosion and static electric field stealth performance is not optimal. So the impressed-current protection method with many auxiliary anodes can not only achieve the effect anti-corrosion, but also helps to reduce the static electric field signal.

\subsection{Impressed-Current Compensation}

This method generally installs the compensation anode directly above the propeller and outputs the compensation current. Through the software simulation analysis, the compensate anode output current is about $21.5 \mathrm{~A}$, when the static electric field intensity becomes the minimum at the water depth 1B. The peak-peak value of the electric field and potential below the keel is shown in Table 6 . Table 6. Peak to peak value of $|\mathrm{E}|$ and $U$ under impressed-current compensation

\begin{tabular}{cccc}
\hline No. & Water depth & Peak-peak value of $|\mathrm{E}|(\mu \mathrm{V} / \mathrm{m})$ & Peak-peak value of $\mathrm{U}(\mathrm{mV})$ \\
\hline 1 & $0.5 \mathrm{~B}$ & 6530.45 & 16.94 \\
2 & $12 \mathrm{~m}$ & 1404.05 & 6.47 \\
3 & $1.0 \mathrm{~B}$ & 362.43 & 2.35 \\
4 & $1.5 \mathrm{~B}$ & 66.12 & 0.76 \\
\hline
\end{tabular}

It can be seen from Table 6 that the peak-to-peak values of the potential $U$ and $|E|$ in different depth planes are reduced with respect to the natural corrosion state, but the decreasing proportion varies. When the water depth increases, the electric field value decays faster. Taking the water depth of $1.0 \mathrm{~B}$ as an example, the electric field is reduced by $56 \%$, and the electric field stealth effect is obvious. This is mainly due to the fact that the impressed-current compensates the current generated by the corrosion of the hull, so that the longitudinal distance of the extreme point is shortened, that 
is, the distance between the equivalent dipole moment is obviously reduced. With the increase of the distance, the stealth effect of the electrostatic field will be obviously increased.

\subsection{Comparison Between Different Conditions Above}

Figure 4 shows the potential of the keel surface in several states. It can be seen that the cathodic protection optimization method based on 8 pairs of auxiliary anodes can make the whole hull at the protected potential, and the anti-corrosion effect is the best. While the hull except the area near propeller is not in the protected potential when using the impressed-current compensation method, which will produce a certain degree of corrosion.

Figure 5 shows the underwater potential signal for several states under the depth of $1.0 \mathrm{~B}$ and horizontal distance of $8 \mathrm{~m}$. It can be seen that the current compensation method makes the static field signal the smallest, and significantly lower than the cathodic protection optimization method.

From the above analysis, we can know that the most effective method in decreasing the ship's static electric field is the impressed-current compensation method, but it will cause some corrosion problem. We will do scaled ship model experiments to examine this conclusion in the following parts.

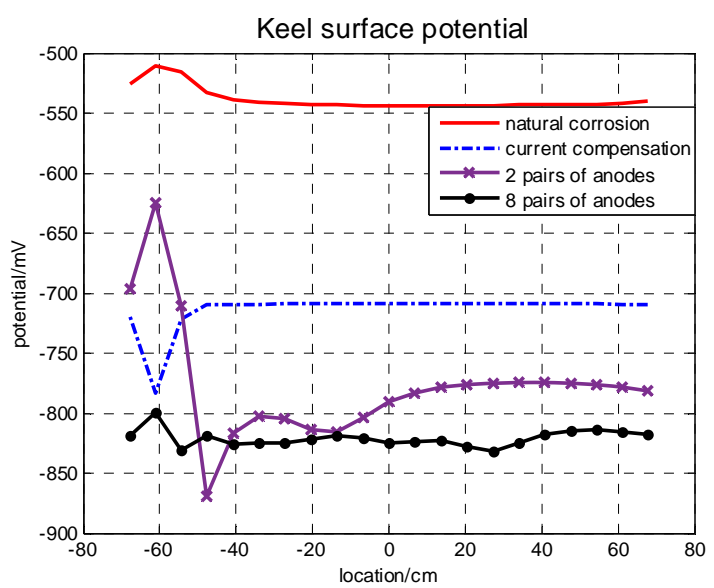

Fig. 4 Keel surface potential

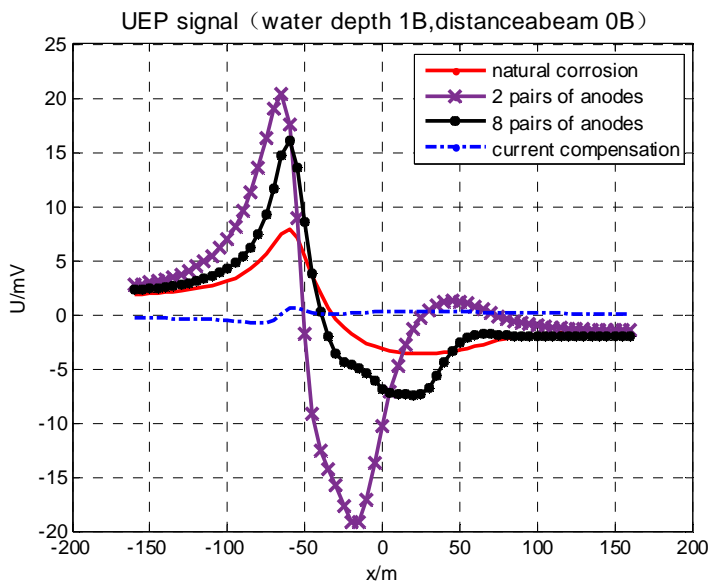

Fig. 5 UEP under different conditions

\section{Ship Model Experiments}

A 1/50 scaled model based on one vessel is used, and the sizes are length $272 \mathrm{~cm}$, width $34 \mathrm{~cm}$ and draft $9.14 \mathrm{~cm}$. The underwater part of the hull uses the same material like real ships (hull with 907 steel, propeller with nickel aluminum bronze), the hull painted ship special paint. The test pool length $12 \mathrm{~m}$, width $6 \mathrm{~m}$, depth $0.75 \mathrm{~m}$, seawater conductivity $2.6 \mathrm{~S} / \mathrm{m}$.

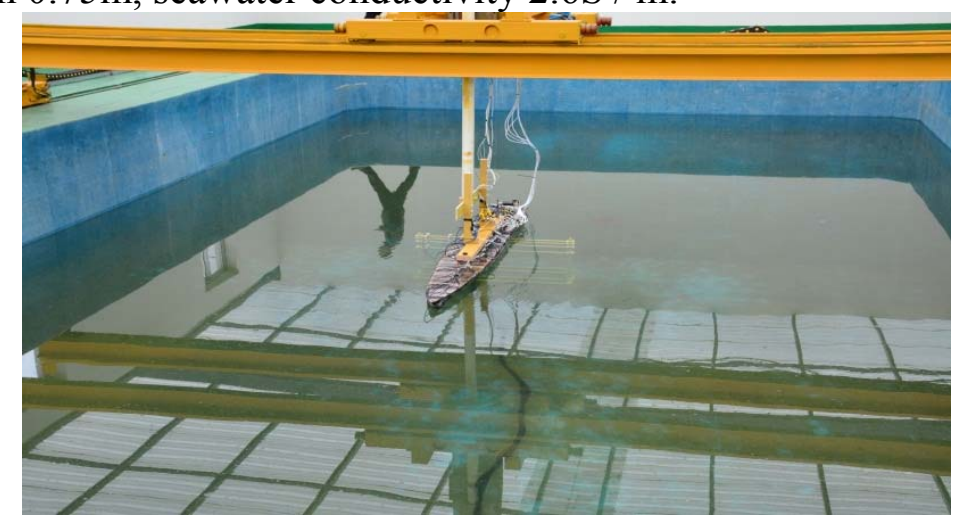

Fig. 6 Scaled ship model and underwater measuring device

$\mathrm{The} \mathrm{Ag} / \mathrm{AgCl}$ electrodes are arranged underwater and the electric field signal at the bottom of the hull keel with a distance of $1 \mathrm{~B}$ (B was $34 \mathrm{~cm}$ wide) was measured. The hull coordinates are consistent with Fig. 2, and the compensating anode and auxiliary anodic mounting positions are shown in Table 7 (left and right sides are symmetrically installed). The number 2 anode in Table 7 acts as a compensating anode when using current compensation method and acts as the secondary auxiliary anode when using cathodic protection optimization method. 
Table 7. Locations of compensation anodes and auxiliary anodes

\begin{tabular}{cccc}
\hline No. & Location $(\mathrm{x}, \mathrm{y})$ & No. & Location $(\mathrm{x}, \mathrm{y})$ \\
\hline 1 & $(-136,5.5)$ & 5 & $(-63,10)$ \\
2 & $(-122,7.5)$ & 6 & $(-32,14)$ \\
3 & $(-119,8)$ & 7 & $(17,9)$ \\
4 & $(-98,12)$ & 8 & $(60,6.5)$ \\
\hline
\end{tabular}

There are 8 pairs of reference electrodes evenly arranged at the keel surface, to measure the surface potential of different areas. We use an multi-channel electrochemical workstation to control the output current. When using current compensation method, the work mode of the workstation is constant current polarization mode, which means the output current is constant and decided by people; when using the cathodic protection optimization method, the work mode is constant potential polarization method, that means the station will make the potential of the hull near the reference electrodes stable. For example, in cathodic protection optimization experiments, the reference potential is set at $-750 \mathrm{mV}$ during the test, then the work station will automatically adjust it output current in order to make the reference potential stable near $-750 \mathrm{mV}$.

In the whole experiments, the underwater electric field signal is measured when the ship model is in different conditions, the natural corrosion, the impressed-current compensation, the cathodic protection and the cathodic protection optimization state. When using the current compensation method, the compensating anode output current is $8 \mathrm{~mA}$; When using the cathodic protection optimization method, different numbers(1pairs, 4pairs and 8pairs) of auxiliary anodes are used, 1pairs of anode using auxiliary anode 2, 4 pairs of auxiliary anode using 1,2,3,4 auxiliary anode, 8 pairs of auxiliary anode using $1 \sim 8$ auxiliary anode.

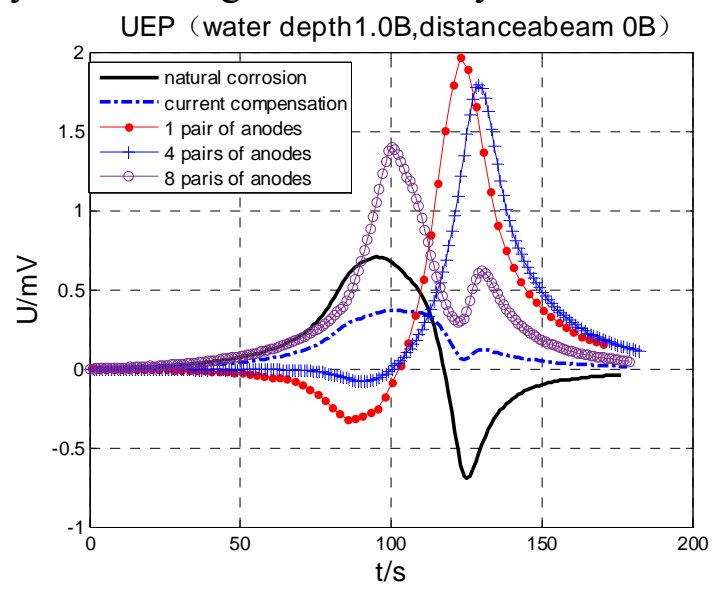

(a) Distance abeam $0 B$

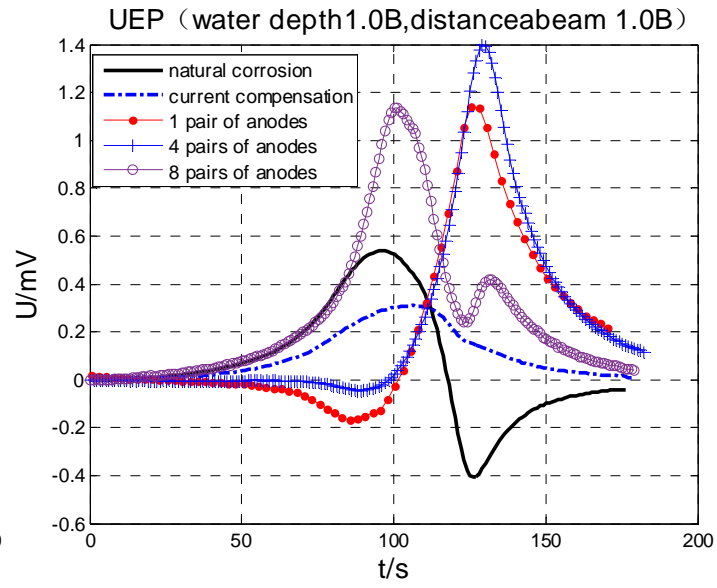

(b) distance abeam 1B

Fig. 7 UEP signals under different conditions and distances

It can be seen from Fig. 7 that the underwater potential signal of the hull is minimum, and is obviously lower than the cathodic protection optimization state when using the impressed-current compensation method. Using the cathodic protection optimization method with 8 pairs of auxiliary anodes, the underwater potential value is $39 \%$ lower than the underwater potential value before optimization ( 1 pair of auxiliary anode), which is in accordance with the previous software simulation results. It can be seen from Fig. 8 that the hull is not in the protected potential when the current compensation method is applied. While the hull is basically at the protected potential when the cathodic protection optimization method is used, and the optimized hull potential fluctuation is smaller at the same time. 


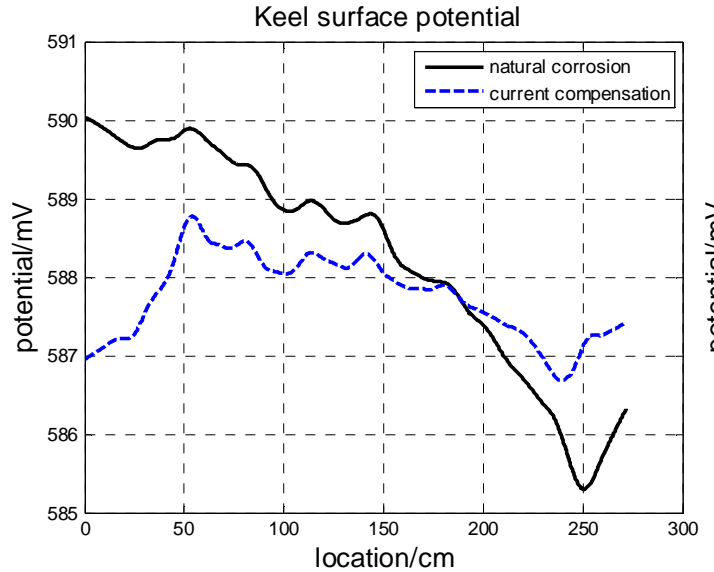

(a) Keel potential under natural corrosion and compensation protection and optimization Fig. 8 keel potential of ship

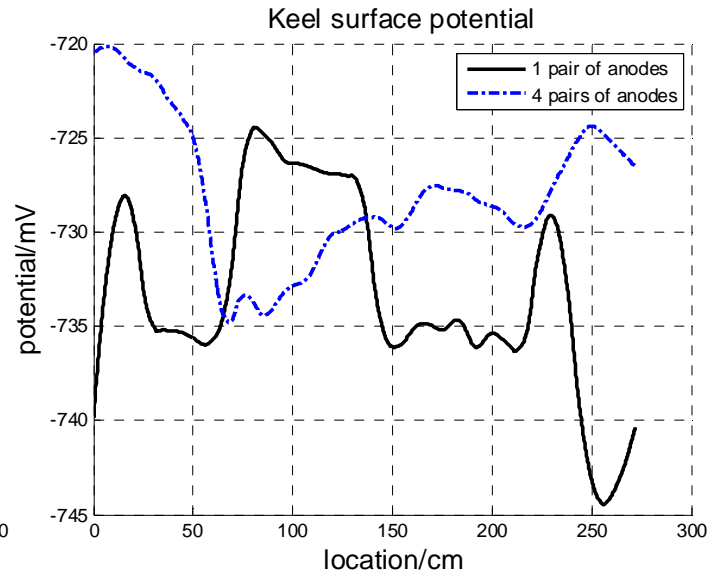

(b) keel potential under cathodic p 
[9]. S.H.Xing, Y.Li, H.Q.Song, et al. Optimizing the quantity,locations and output currents of anodes to improve cathodic protection effect of semi-submersible Crane vessel [J]. Ocean Engineering, $2016,113: 144-150$.

[10]. Xing S, Wu J, Yan Y. Optimization of a ship's ICCP system to minimize electrical and magnetic signature by mathematical simulation [J]. WIT Transactions on Engineering Sciences, 2009, 65: 69-78.

[11]. Parlongue J, Bortels L.A numerical modeling technique to evaluate and control the electromagnetic signature [C].UDT 2010, Hamburg, Germany, 2010.

[12]. LUO Yi, Yimiluofu. Waxili. Research of anti-minesweeping in ship's electric field detecting system [J]. Journal of Wuhan University of technology (Transportation Science \& Engineering),2011,35 (3):542-545.

[13]. WU Jiang, LIU Guipu, ZHANG Jie. The research of high temperature resistant zinc base alloy Sacrificial anode [J]. NON-FERROUS M1NING AND METALLURGY, 2007, 23 (30): 34-39.

[14]. SUN Jianhong, ZHEN Wei, WANG Xiaopeng. Optimum Design of Anti-corrosion and Cathodic Protection for Ships [J]. Chinese Journal of Ship Research, 2007, 2 (4); 60-67. 